\title{
Pathological complete response induced by first-line chemotherapy with single agent docetaxel in a patient with advanced non small cell lung cancer
}

\author{
Ferdinando Riccardi ${ }^{1 *}$, Giuseppe Di Lorenzo', Carlo Buonerba', Guglielmo Monaco², Roberto Monaco², \\ Mimma Rizzo ${ }^{1}$, Sarah Scagliarini ${ }^{1}$, Florinda Scognamiglio', Marilena Di Napoli' ${ }^{1}$ Giacomo Carteni'1
}

\begin{abstract}
Background: Defining the optimal treatment for patients with inoperable non small cell lung cancer (NSCLC), presenting with metastatic mediastinal lymph nodes, is challenging. Nevertheless, preoperative chemotherapy or radiotherapy might offer a chance for these patients for radical surgical resection and, possibly, complete recovery.

Case Presentation: A 62-year old man with IIIA-N2 inoperable NSCLC was treated with first-line single agent docetaxel. A platinum-based treatment, though considered more active, was ruled out because of renal impairment. The patient tolerated the treatment very well and, although his initial response was not impressive, after 14 cycles he obtained a complete clinical response, which was confirmed pathologically after he underwent surgical lobectomy.

Conclusion: In non-operable NSCLC patients not eligible for a platinum-based treatment, single-agent docetaxel can provide complete pathologic responses. Failure to obtain a response after the first few cycles should not automatically discourage to continue treatment.
\end{abstract}

\section{Introduction}

In non-small cell lung cancer (NSCLC), mediastinal lymphnode involvement comprises a wide spectrum of severity. In fact, while $9 \%$ of patients with IIIA-N2 NSCLC is candidate for surgery at diagnosis, with a 5year survival of $20-30 \%$, the majority of patients with stage IIIA-N2 and IIIB-N2 tumors cannot undergo upfront surgical resection and present a 5-year survival rate of about $5 \%[1]$. There is a growing body of evidence that suggests that neoadjuvant chemotherapy or radiotherapy or chemoradiotherapy prior to surgery can be advantageously employed in patients with stage IIIA-N2 disease[2]. We herein describe an unusual case of pathological complete response induced by single agent docetaxel chemotherapy in a patient with diagnosis of NSCLC initially judged not fit for surgical resection.

\footnotetext{
* Correspondence: nando.riccardi@alice.it

'UOC Oncologia, Ospedale Cardarelli, Napoli, Italy
}

\section{Case Presentation}

A 62-year-old man was referred to Cardarelli Hospital, Naples, in June 2008. He presented a 4-month history of non productive cough, progressive shortness of breath, increasing abdominal girth and anorexia. He was mildly dyspnoeic at rest and complained about severe asthenia. There was no alcohol abuse in the previous ten years, while he presented an 80-pack-a year history of cigarette use, as he had smoked since the age of 18 until recently. An abnormal shadow appeared on the patient's chest Xray, while a CT scan revealed a right hilar tumor, measuring $92 \times 66 \mathrm{~mm}$, as shown in Figure 1 .

A fiberoptic bronchoscopy indicated the presence of an endobronchial lesion infiltrating the upper lobar bronchus of the right lung. Pathological analysis with CT-guided fine-needle aspiration biopsy (FNAB) of the collected specimens showed that the tumor was a poorly differentiated squamous cell carcinoma. There was no evidence of extra thoracic metastasis on brain MRI, abdominal CT and FDG-PET scans. Therefore, the patient had a stage IIIA-N2 NSCLC. 

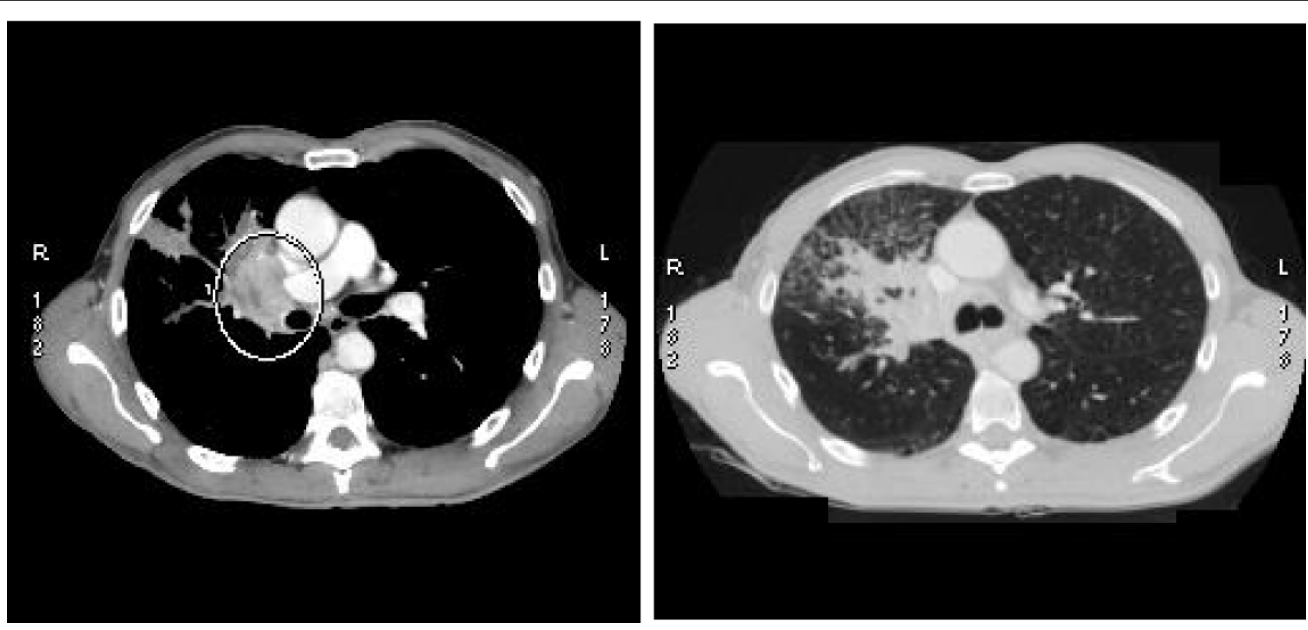

Figure 1 CT scan on June 2008

Blood tests revealed a mild renal failure with an estimated creatinine clearance of $47 \mathrm{ml} / \mathrm{min}$. Considering the impaired renal function, a platinum-based treatment was ruled out. Therefore, the patient was started on single-agent docetaxel induction chemotherapy ( 75 $\mathrm{mg} / \mathrm{sqm}$ over $60 \mathrm{~min}$ on day 1 , every 3 weeks). The first evaluation was made after four cycles. In September 2008, a CT scan showed a partial response of the carcinoma, which appeared to measure $65 \times 41 \mathrm{~mm}$. The safety profile was good, with patient reporting grade 1 anemia, grade 3 neutropenia without fever, weight loss inferior to $10 \%$ and asthenia. Therefore, the treatment was continued for four additional cycles. In January 2009, a CT scan showed an impressive shrinkage of the hilar mass, measuring $35 \times 30 \mathrm{~mm}$. There also was a marked clinical improvement, as the cough and the dyspnoea had disappeared and the patient reported a general feeling of wellness. Considering the patient's good compliance, it was decided to continue the same treatment until progression or unacceptable toxicity. After 14 cycles, both CT and PET scans showed further tumor response, as the right hilar mass measured only $16 \times 10 \mathrm{~mm}$, and the patient was finally judged to be eligible for surgery (figures 2 and 3). The chest surgeon decided to perform a right lobectomy with mediastinal lymph node sampling. On pathological examination, the response to induction chemotherapy was complete.

\section{Discussion}

Preoperative, platinum-based combination chemotherapy is safe and active in NSCLC, although a randomized trial reported a modest, not statistically significant excess of post-surgical morbidity and mortality[3]. As single-agent therapy is associated to a lower response rate, but also to lower toxicity[4], single-agent docetaxel
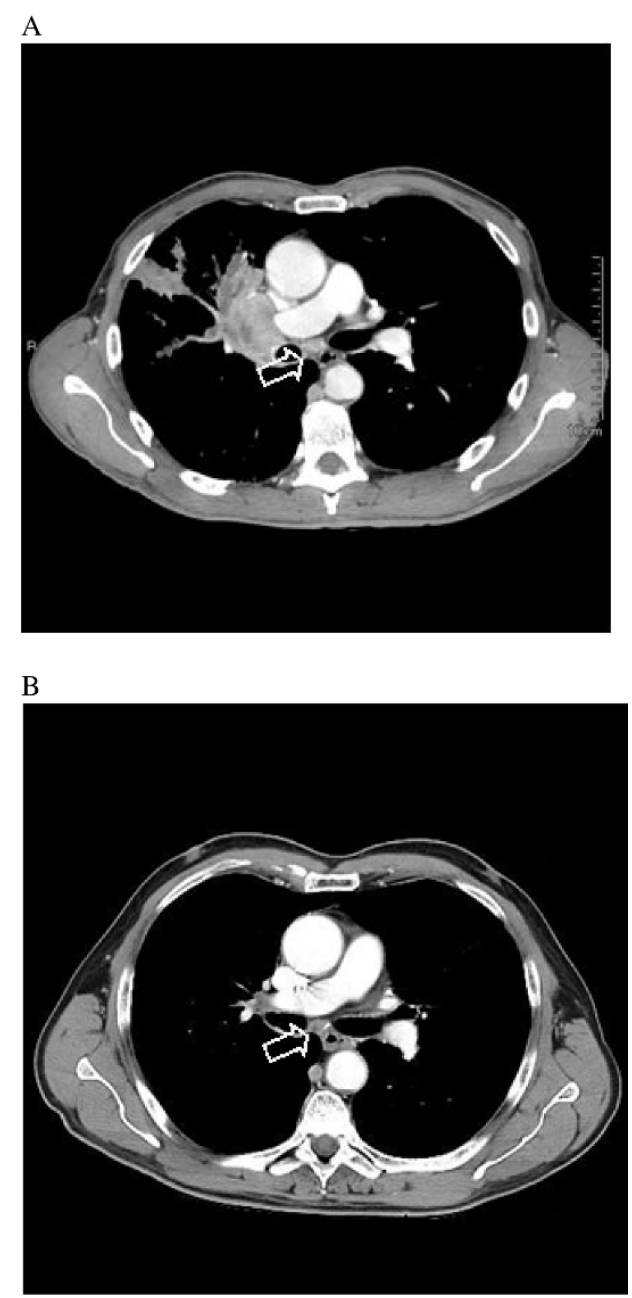

Figure 2 Chest computed tomography scan (A) before treatment of docetaxel (B) 10 months after treatment. The arrows show the mediastinal lymph node metastasis that gradually reduced in size. 


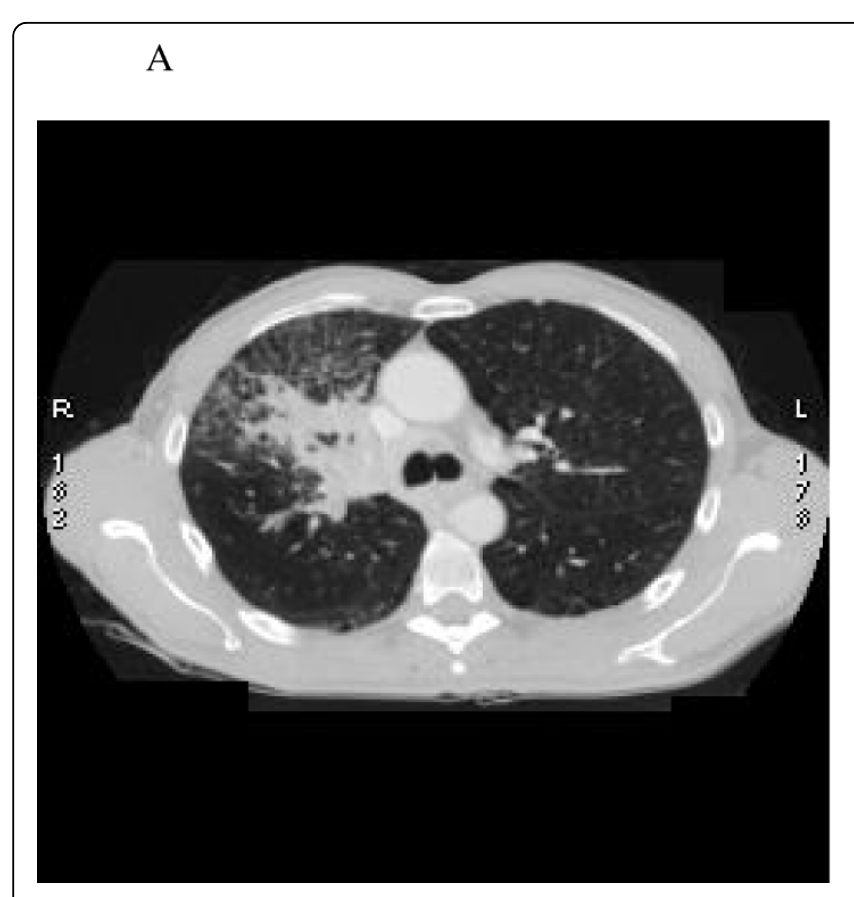

B

Figure 3 (A) CT scan June 2008 before therapy. (B) CT scan April 2009 after therapy.

chemotherapy might be feasible for preoperative therapy, especially in the context of an early stage disease to be cured with surgery and adjuvant therapy, as well. A phase III trial randomized patients with stage IIIA or locally treatable IIIB NSCLC to neoadjuvant docetaxel (up to three 3 -weekly cycles at $100 \mathrm{mg} / \mathrm{m}^{2}, 134$ patients) or no chemotherapy (140 patients) prior to surgery/ curative-intention radiotherapy. Treatment proved to be safe and well tolerated, but this trial showed only a trend in survival prolongation (14.8 months in the chemotherapy group vs. 12.6 months in the control group, not statistically significant)[5]. A multicenter phase III trial indicated that patients with advanced NSCLC receiving the combination of docetaxel and cisplatin (DC) had a statistically significant improvement in objective response rate compared with patients treated with docetaxel alone (D), although there was no statistically significant difference in overall survival (36\% vs. $18 \%$ and 10.5 vs. 8.0 months, respectively). Furthermore, patients treated with single-agent docetaxel had a more favorable toxicity profile than patients treated with DC. In particular, there were important differences in the incidence of: (a) grade 2 anemia, (b) grade 3/4 nausea/ vomiting, diarrhea, and neurotoxicity, (c) nephrotoxicity of any grade and (d) treatment-related deaths (5 in the DC arm vs 1 in the D arm)[6].

Similarly, the toxicity profile of the monotherapy arm in the Lilenbaum [7] study was more favorable compared with that of the combination arm, with no difference in survival.
Although it is generally believed that best responses are obtained in patients who initially respond to docetaxel treatment, the case presented herein proves how an unexpected, striking complete pathologic response can be achieved with a long-term treatment, which was substantially well tolerated. Such an observation, if confirmed by large-sample studies, might indicate how an unsatisfactory initial response, but not progressive disease, does not constitute a reliable predictive factor for response, as a great improvement in response itself can still be obtained, if treatment is continued. Noteworthy, such a result appears to be in contrast with observations regarding neo-adjuvant docetaxel-based chemotherapy in other inoperable malignant tumors, such as breast cancer[8].

Surprisingly, a complete pathologic response was not obtained with a platinum-based regimen, but with single-agent docetaxel, which is not considered to be the first-line chemotherapy for non-operable patients with NSCLC. The search for either molecular or genetic markers predictive for docetaxel sensitivity might constitute future targets of investigation.

Finally, we cannot but underline our decision not to suspend treatment as soon as the patient was considered to be eligible for surgery. In fact, our choice to continue docetaxel chemotherapy resulted in further tumor shrinkage, with no additional toxicity, and gave the patient the possibility to undergo a lobectomy rather than a pneumectomy, with the obvious advantages of a less invasive and more limited surgical operation. Our 
patient obtained a striking response to docetaxel as firstline monotherapy treatment and could undergo an upper right lobectomy with radical intent. Microscopic examination showed a pathological complete response of the neoplasia.

\section{Conclusion}

Our results suggest that physicians should be aware of potential objective responses to Docetaxel, as first-line, for patients with limitations to receive platinum-based regimens, even after the tumor does not seem to be reduced in size at the beginning phase of the treatment.

\section{Consent}

Written informed consent was obtained from the patient for publication of this case report and accompanying images. A copy of the written consent is available for review by the Editor-in-Chief of this journal.

\section{Conflict of interests}

The authors declare that they have no competing interests.

\section{Author details}

${ }^{1}$ UOC Oncologia, Ospedale Cardarelli, Napoli, Italy. ${ }^{2}$ UOC Chirurgia Toracica, Ospedale Cardarelli, Napoli, Italy. ${ }^{3}$ UOC Anatomia Patologica, Ospedale Cardarelli, Napoli, Italy.

\section{Authors' contributions}

FR, GDL and GC conceived of the study, coordination and writing manuscript;

GM diagnosed the cancer with fiberoptic bronchoscopy and decided to perform a right lobectomy; RM: Pathologist and author of diagnosis of poorly differentiated squamous cell carcinoma;CM, MR, SS, FS, MDN esamined the patient at follow-up.

Received: 12 November 2009

Accepted: 5 February 2010 Published: 5 February 2010

\section{References}

1. Albain KS: Induction therapy followed by definitive local control for stage III non-small-cell lung cancer. A review, with a focus on recent trimodality trials. Chest 1993, 103(Suppl):43-50S

2. Eberhardt W, Gauler T, Pöttgen C, Krbek T, Korfee S, Stamatis G, Stuschke M: Multimodality treatment of stage IIIA and IIIB non-small cell lung cancer. J Thorac Oncol 2007, 2(5 Suppl):S35-6.

3. Depierre A, Milleron B, Moro-Sibilot D, Chevret S, Quoix E, Lebeau B, Braun $D$, Breton JL, Lemarié $E$, Gouva $S$, Paillot $N$, Bréchot JM, Janicot $H$, Lebas FX, Terrioux P, Clavier J, Foucher P, Monchâtre M, Coëtmeur D, Level MC, Leclerc P, Blanchon F, Rodier JM, Thiberville L, Villeneuve A Westeel V, Chastang C, French Thoracic Cooperative Group: Preoperative chemotherapy followed by surgery compared with primary surgery in resectable stage I (except T1N0), II, and IIla non-small-cell lung cancer. J Clin Oncol 2002, 20:247-53.

4. Delbaldo C, Michiels S, Syz N, Soria JC, Le Chevalier T, Pignon JP: Benefits of adding a drug to a single-agent or a 2-agent chemotherapy regimen in advanced non-small-cell lung cancer: a meta-analysis. JAMA 2004, 292:470-84.

5. Mattson KV, Abratt RP, ten Velde G, Krofta K: Docetaxel as neoadjuvant therapy for radically treatable stage III non-small-cell lung cancer: a multinational randomised phase III study. Ann Oncol 2003, 14:116-22.

6. Georgoulias V, Pallis AG, Kourousis C, Alexopoulos A, Ardavanis A, Agelidou A, Agelidou M, Toumbis M, Tzannes S, Pavlakou G, Ziotopoulos P,
Tzelepatiotis E, Samaras N: Docetaxel versus docetaxel/cisplatin in patients with advanced non-small-cell lung cancer: preliminary analysis of a multicenter, randomized phase III study. Clin Lung Cancer 2003, 4:288-93.

7. Lilenbaum RC, Herndon JE, List MA, Desch C, Watson DM, Miller AA, Graziano SL, Perry MC, Saville W, Chahinian P, Weeks JC, Holland JC, Green MR: Single-agent versus combination chemotherapy in advanced non-small-cell lung cancer: the cancer and leukemia group B (study 9730). J Clin Oncol 2005, 23:190-6.

8. Heys SD, Hutcheon AW, Sarkar TK, Ogston KN, Miller ID, Payne S, Smith I, Walker LG, Eremin O: Aberdeen Breast Group. Neoadjuvant docetaxel in breast cancer: 3-year survival results from the Aberdeen trial. Clin Breast Cancer 2002, , Suppl: 569-74

doi:10.1186/1477-7819-8-8

Cite this article as: Riccardi et al:: Pathological complete response induced by

first-line chemotherapy with single agent docetaxel in a patient with advanced non small cell lung cancer. World Journal of Surgical Oncology $20108: 8$.

\section{Submit your next manuscript to BioMed Central and take full advantage of:}

- Convenient online submission

- Thorough peer review

- No space constraints or color figure charges

- Immediate publication on acceptance

- Inclusion in PubMed, CAS, Scopus and Google Scholar

- Research which is freely available for redistribution 